major alteration of chain configuration and yet shifts occur in the frequencies of the $\mathrm{CO}$ and $\mathrm{NH}$ bonds similar to those expected for the change from $\alpha$ - to $\beta$-type chain configurations. Further, chainfolding of the type indicated by the model based on the $\beta$ configuration may well occur in at least part of the insulin molecule (Hodgkin \& Oughton, 1956). Unlike the $\alpha$-helix, this type of folding would permit very easy formation of S-S links between cysteyl residues placed five residues apart in a polypeptide chain, exactly the interval found by Sanger, Smith \& Kitai (1954) in the A chain of insulin.

\section{REFERENCES}

Abbott, N. B. \& Ambrose, E. J. (1953). Proc. Roy. Soc. A, 219, 17.

Akimova, L. N. \& Gavrilov, N. I. (1954). Zh. Obshch. Khim. 24, 1064.
Ambrose, E. J. \& Elliott, A. (1951). Proc. Roy. Soc. A, 208, 75.

Donohue, J. (1953). Proc. nat. Acad. Sci., Wash., 39, 470.

Ehrlich, G. \& Sutherland, G. B. B. M. (1953). Nature, Lond., $172,671$.

Hodgkin, D. C. \& Oughton, B. (1956). Ciba Foundation Colloq. Endocrin. 9, 133.

Huggins, M. L. (1943). Chem. Rev. 32, 195.

Ioanisiani, P. G., Gavrilov, N. I. \& Plekhan, M. I. (1954). Zh. Obshch. Khim. 24, 364.

Koltun, N., Waugh, D. F. \& Bear, R. S. (1954). J. Amer. chem. Soc. 76, 413.

Pauling, L. \& Corey, R. B. (1951). Proc. nat. Acad. Sci., Wash., 37, 729.

Pauling, L., Corey, R. B. \& Branson, H. R. (1951). Proc. nat. Acad. Sci., Wash., 37, 205.

Reznichenko, M. S. (1954). Zh. Obshch. Khim. 24, 1694.

Sanger, F., Smith, L. F. \& Kitai, R. (1954). Biochem. J. 58, vi.

Silaev, A. B., Trefilova, L. S. \& Ioanisiani, P. G. (1951). Uchen. Zap. mosk. Univ. vIII, 151, 365.

\title{
The Ionization of Acidic Metmyoglobin
}

\author{
IONIC-STRENGTH CHARGE EFFECTS
}

\author{
By P. GEORGE* AND G. I. H. HANANIA $\dagger$ \\ Department of Colloid Science, University of Cambridge
}

(Received 10 September 1956)

We have shown in a previous publication [George \& Hanania, 1952, subsequently referred to as paper (1)] that measurements of the equilibrium concentrations of acidic and alkaline metmyoglobin (MetMb), under conditions of very low ionic strength, $I$, yield a constant value for the ionization constant only within a narrow range of $\mathrm{pH}$ from about $8 \cdot 6$ to $9 \cdot 3$. In more alkaline solutions progressively higher $\mathrm{p} K$ values were obtained, and the trend in more acidic solutions was towards lower $\mathrm{p} K$ values.

From determinations of the mean $\mathrm{p} K$ values between $\mathrm{pH} 8.6$ and 9.3 at very low ionic strengths, the limiting slope of a plot of $\mathrm{p} K$ against $\sqrt{ } I$ showed that the ionization, which is believed to be that of a water molecule co-ordinated to the haemin iron,

$$
\mathrm{Fe}^{+}\left(\mathrm{H}_{2} \mathrm{O}\right)=\mathrm{FeOH}+\mathrm{H}^{+},
$$

is accompanied by the change from -2 to -3 in the effective charge on the iron. The effective charge determined in this way has been called the ionicstrength charge $Z$ (cf. Barnard, 1944). However, the formal charge on the ferric iron atom is not -2

* Present address: Department of Chemistry, University of Pennsylvania, Philadelphia.

$\dagger$ Present address: Department of Chemistry, College of Arts and Sciences, Baghdad, Iraq. but +1 , since two of its three positive charges can be regarded as neutralized by negative charges on two pyrrolic nitrogen atoms of the porphyrin ring. This difference is not altogether unexpected, since the ionization occurs about two $\mathrm{pH}$ units on the alkaline side of the isoelectric point of myoglobin, and the net regative charge on the molecule, which the acid-base titration curve suggests is about 10 (George \& Irvine, 1955), may be considered to influence the reactions of the haemin iron.

Our studies of the formation of metmyoglobin fluoride (George \& Hanania, 1954a-c) substantiated this idea, for in the $\mathrm{pH}$ range $6 \cdot 5-7 \cdot 5$, which spans the isoelectric point, the change in $Z$ was found to be approximately equal to the corresponding change in formal charge, +1 to 0 , according to the equation

$$
\mathrm{Fe}^{+}\left(\mathrm{H}_{2} \mathrm{O}\right)+\mathrm{F}^{-}=\mathrm{FeF}+\mathrm{H}_{2} \mathrm{O} \text {. }
$$

That is, somewhere between pH 7.5 and 8.6 the ionization of acidic groups on the molecule alters the value of $Z$ for MetMb from +1 to -2 . This in turn suggests that the variation of $\mathrm{p} K^{\prime}$ with $\mathrm{pH}$, at low ionic strengths and outside the range of $\mathrm{pH} 8 \cdot 6-9 \cdot 4$, might well be due to changes in $Z$ brought about by the ionization of these groups. We present below some detailed measurements made to test this hypothesis. 


\section{MATERIALS AND METHODS}

Preparation of metmyoglobin. The preparation from horse hearts was carried out as described by George \& Irvine (1952) with the following slight modifications. Instead of being taken up finally in a pH 5.7 buffer, the solid MetMb was dissolved in a small quantity of $\mathrm{NaCl}$ solution (1\%, w/w); Seitz filtration was omitted, and the solutions were stored in sealed ampoules at $-10^{\circ}$ rather than at $0^{\circ}$. This treatment produced little or no denaturation, and the characteristic extinctions were reproducible to within $1 \%$ over a period of many months. When required, portions of the stock were exhaustively dialysed and kept in water at $0^{\circ}$.

The concentrations of all MetMb solutions are expressed in terms of their haematin content and refer to a molecular weight of 17000 . However, it should be pointed out that in paper 1 concentrations of MetMb solutions were based on the standards of Duve (1948), but assuming a molecular weight of 17000 instead of the value 16200 used by Duve. Concentrations determined in this way were therefore low by about $4 \%$, and the extinction coefficients were correspondingly high.

Theorell \& Åkeson (1955) have recently described an electrophoretic separation of MetMb into three fractions, the main fraction normally accounting for approximately $80 \%$ of the haemoprotein. Their method of preparation differs from ours in omitting the treatment with $\mathbf{3} \mathrm{M}$ phosphate buffer, pH 6.8. Although simple paper electrophoresis had indicated that the present preparations were homogeneous, it is nevertheless possible that these were also mixtures and the question arises as to what effect this would have on results obtained with them. First, the concentration determined as haematin iron via the pyridine haemochromogen is not affected, but the extinction coefficients and isosbestic points quoted below may be average values. However, we have found these values to be reproducible to within $1 \%$ for a number of preparations, which suggests that if several myoglobins are present the same mixture is obtained each time as far as can be judged from spectroscopic characteristics. Secondly, in our previous study in paper 1 , the result that $n=1$ for the ionization between pH 8.6 and 9.3 over the entire ionic-strength range indicates that, within experimental error, all the iron in the metmyoglobin shows the same chemical affinity. For this reason we believe that thermodynamic data obtained with the present preparations are truly representative of myoglobin, and that if several myoglobins are actually present the different protein components only influence very slightly the reactivity of the haemin iron atom. The data for the ionization even of metmyoglobin and methaemoglobin are quite similar, as shown in Table 1, whereas there are far greater differences between these two proteins, e.g. solubility, than there are between the three myoglobin fractions.

Spectrophotometric measurements. These were carried out as described in paper 1 with a Unicam quartz spectrophotometer and a water-circulating device for controlling temperature in the cell compartment to $\pm 0 \cdot 1^{\circ}$. The absorption spectra of acidic and alkaline MetMb were carefully mapped out from 950 to $240 \mathrm{~m} \mu$., and the positions of the bands and their corresponding molar extinction coefficients are given in Table 2. Isosbestic points were located at the following wavelengths: $858,675,626,523,494,419$ and $269 \mathrm{~m} \mu$.

For the purposes of measurement, weakly buffered MetMb solutions about $50 \mu \mathrm{M}$ were used. The wavelength $584 \mathrm{~m} \mu$. was chosen for comparing optical densities, and all measurements were made in $10 \mathrm{~mm}$. glass cells, against water as a blank.

Buffer solutions. These were prepared as described in paper 1. For the $\mathrm{pH}$ range 8-10 borate buffers were made from mixtures of $\mathrm{H}_{3} \mathrm{BO}_{3}$ and $\mathrm{NaOH}$, and for lower $\mathrm{pH}$ values mixtures of $\mathrm{NaH}_{2} \mathrm{PO}_{4}, 2 \mathrm{H}_{2} \mathrm{O}$ and $\mathrm{NaOH}$ were used. All chemicals were of A.R. quality, and the water was distilled and then passed through a column of exchange resin. Ionic strengths were reckoned on the basis of contributions from the buffer ions, and were adjusted by the addition of the requisite small quantities of $\mathrm{NaCl}$.

Measurement of $\mathrm{pH}$. This was carried out as described in paper 1. The suggestions of Bates, Pinching \& Smith (1950) were closely followed with regard to the standardization of the $\mathrm{pH}$ scale, and no further corrections were applied for the change in liquid-junction potentials with the changing ionic strength of the solutions.

\section{RESULTS}

By the procedure described in paper 1, values for the ionization constant were calculated from the measured $\mathrm{pH}$ of the solution and the spectrophotometrically determined ratio of the concentrations of acidic MetMb $\left(C_{\mathrm{HP}}\right)$ and alkaline MetMb $\left(C_{\mathrm{P}}\right)$, i.e.

$$
\mathrm{p} K^{\prime}=\mathrm{pH}+\log C_{\mathrm{HP}} / C_{\mathrm{P}} \text {. }
$$

In the present study, measurements were extended over a much wider $\mathrm{pH}$ range, about $\mathrm{pH} 7-10$, and were made at eight ionic strengths of the buffer ranging from 0.40 to 0.002 . The data at three ionic

Table 1. Thermodynamic data for the ionization of metmyoglobin and methaemoglobin at $20^{\circ}$ (George \& Hanania, 1952, 1953)

$\begin{array}{lccc} & \Delta G^{\circ}\left(\mathrm{kcal} . \mathrm{mole}^{-1}\right) & \Delta H\left(\mathrm{kcal}_{\mathrm{mole}}^{-1}\right) & \Delta S^{\circ}\left(\mathrm{cal}_{\mathrm{mole}}^{-1} \mathrm{degree}^{-1}\right) \\ \text { MetMb } & 12 \cdot 1 \pm 0 \cdot 04 & 5 \cdot 75 \pm 0 \cdot 67 & -21 \cdot 7 \pm 2 \cdot 4 \\ \text { MetHb } & 11 \cdot 9 \pm 0 \cdot 03 & 3 \cdot 91 \pm 0 \cdot 49 & -27 \cdot 2 \pm 1 \cdot 8\end{array}$

Table 2. Millimolar extinction coefficients $\left(10^{-3} \epsilon\right)$ of acidic MetMb at $\mathrm{pH} 6 \cdot 0$ and alkaline MetMb at $\mathrm{pH} 11 \cdot 0$, corresponding to band-absorption maxima of wavelength $\lambda$

\begin{tabular}{|c|c|c|c|c|c|c|c|c|c|}
\hline$\lambda(\mathrm{m} \mu.) \quad \ldots$ & 823 & 633 & 594 & 584 & 543 & 503 & $413_{5}$ & $409_{5}$ & 280 \\
\hline $\begin{array}{l}\text { Acidic MetMb } \\
\text { Alkaline MetMb }\end{array}$ & $\overline{0.75}$ & $\begin{array}{l}3.52 \\
-\end{array}$ & $\overline{8.50}$ & $\begin{array}{l}2 \cdot 66 \\
8.50\end{array}$ & $\overline{8.80}$ & $\underline{9 \cdot 18}$ & $\overline{91.0}$ & 166 & $\begin{array}{l}32 \cdot 2 \\
34 \cdot 9\end{array}$ \\
\hline
\end{tabular}


Table 3. Values of $\mathrm{p} K^{\prime}$ for the ionization of acidic MetMb calculated from equation 2 of paper 1 , at various $\mathrm{pH}$ values and at three ionic strengths

Values in middle section* are from paper 1 , and cover the $\mathrm{pH}$ range from about $8 \cdot 5$ to $9 \cdot 0 . T=20^{\circ}$.

\begin{tabular}{lc}
\multicolumn{2}{c}{$I=0.40$} \\
$\mathbf{p H}$ & $\mathrm{p} K^{\prime}$ \\
$7 \cdot 56$ & $8 \cdot 99$ \\
$7 \cdot 80$ & 8.98 \\
$8 \cdot 01$ & 8.99 \\
$8 \cdot 18$ & 8.99 \\
$8 \cdot 5^{*}$ & $8.98 \pm 0.01$ \\
$9 \cdot 0^{*}$ & \\
$9 \cdot 53$ & 8.99 \\
$9 \cdot 63$ & 8.98 \\
$9 \cdot 76$ & 8.97
\end{tabular}

\begin{tabular}{lc}
\multicolumn{2}{c}{$I=0.01$} \\
pH \\
$7 \cdot 73$ & $\mathrm{p} K^{\prime}$ \\
$8 \cdot 10$ & $8 \cdot 83$ \\
$8 \cdot 30$ & $8 \cdot 87$ \\
$8 \cdot 44$ & $8 \cdot 89$ \\
$8 \cdot 5^{*}$ & $8 \cdot 89$ \\
$9 \cdot 0^{*}$ & $8 \cdot 89 \pm 0 \cdot 01$ \\
$9 \cdot 32$ & $8 \cdot 88$ \\
$9 \cdot 52$ & 8.90 \\
$9 \cdot 70$ & 8.92 \\
$9 \cdot 80$ & 8.94
\end{tabular}

\begin{tabular}{|c|c|}
\hline \multicolumn{2}{|c|}{$I=0.002$} \\
\hline $\mathrm{pH}$ & $\mathrm{p} K^{\prime}$ \\
\hline $\begin{array}{l}7 \cdot 36 \\
8 \cdot 04 \\
8 \cdot 28 \\
8 \cdot 43\end{array}$ & $\begin{array}{l}8 \cdot 76 \\
8 \cdot 85 \\
8 \cdot 91 \\
8 \cdot 91\end{array}$ \\
\hline $\left.\begin{array}{l}8 \cdot 5^{*} \\
9 \cdot 0^{*}\end{array}\right\}$ & $8.93 \pm 0.02$ \\
\hline $\begin{array}{l}9 \cdot 07 \\
9 \cdot 19 \\
9 \cdot 31 \\
9 \cdot 43 \\
9 \cdot 60\end{array}$ & $\begin{array}{l}8 \cdot 93 \\
8 \cdot 95 \\
8 \cdot 95 \\
8 \cdot 98 \\
9 \cdot 01\end{array}$ \\
\hline
\end{tabular}

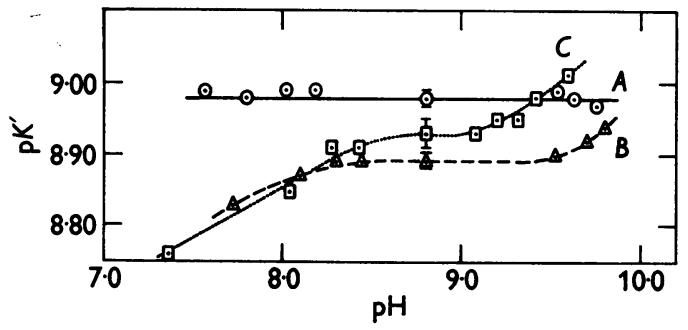

Fig. 1. Values from Table 3 are plotted to show the constancy of $K^{\prime}$ with $\mathrm{pH}$ at high ionic strengths, $I=0.40$ $(A)$, and the progressive spread of $\mathrm{p} K^{\prime}$ values over a $\mathrm{pH}$ range at constant $I$ in solutions of decreasing ionic strength, $I=0.01(B)$ and $I=0.002(C)$. The values taken from paper 1, with their limits of error, are plotted at pH 8.8.

strengths, the two extreme values and an intermediate one, are given in Table 3 and are plotted in Fig. 1.

The results are in good agreement with those of paper 1, and they confirm the previous conclusion, namely that the ionization constant is independent of pH only in the presence of appreciable concentrations of a neutral salt. Thus at $I=0.40$ (at $20^{\circ}$ ) the mean value of $p K^{\prime}$ is $8.98 \pm 0.01$ throughout the

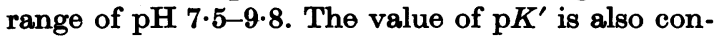
stant with $\mathrm{pH}$ at lower salt concentrations until about $I=0.02$, when a definite spread in the values becomes noticeable, both below pH 8 and above pH 9. The spread becomes progressively greater at lower ionic strengths and, as can be seen in Fig. 1, it is quite marked at $I=0.002$.

The effect is better illustrated when the data are plotted at constant pH. By interpolating between experimental values of $\mathrm{p} \boldsymbol{K}^{\prime}$, and in one case by using a slight extrapolation, two sets of $p K^{\prime}$ values as a function of ionic strength were obtained, at $\mathrm{pH} 7 \cdot 8$ and 9.8. The plots are shown in Fig. 2, which also includes the curve at $20^{\circ}$ from paper 1. Extrapola-

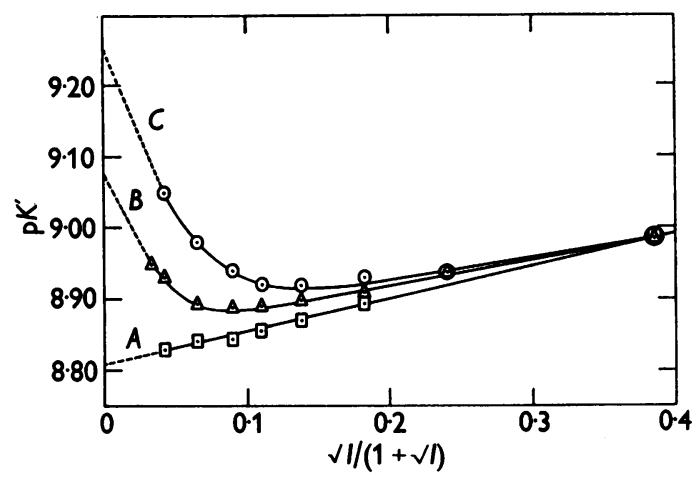

Fig. 2. Variation of $\mathrm{p} K^{\prime}$ at $20^{\circ}$ with ionic strength at pH $7.8(A)$, at pH values between 8.5 and $9.0(B)$, and at pH 9.8 $(C)$, obtained by interpolation (at constant $\mathrm{pH}$ ) from curves of the type shown in Fig. 1. Curve $B$ is taken directly from paper 1. The limiting linear slopes are approximately $+0.5,-2.5$ and -4.5 in $A, B$ and $C$ respectively.

tion of these curves to $I=0$, assuming that they are linear at very low ionic strength, gives the approximate $\mathrm{p} K_{0}$ values of 9.25 at $\mathrm{pH} 9.8$ and 8.81 at pH 7.8, which are to be compared with the value 9.07 from paper 1 obtained in the intermediate $\mathrm{pH}$ range. Likewise the approximate limiting slopes of the lines are about -4.5 at $\mathrm{pH} 9.8$ and +0.5 at pH 7.8, as compared with -2.5 in the intermediate range.

\section{DISCUSSION}

The above results and similar data may be used to furnish a simple and semi-quantitative measure of the influence of a protein on the reactivity or affinity of its active site. First, however, it is necessary to show that this remarkable effect of $\mathrm{pH}$ on the ionization of acidic MetMb is a genuine effect of the ionization of acidic groups on the free energy of ionization of the iron-bound water molecule, and 
is not due merely to shifts in the position or intensity of the absorption bands of acidic or alkaline MetMb at very low ionic strengths.

The likelihood that this is a genuine chemical effect may be inferred from a comparison between methaemoglobin (MetHb) and MetMb. In the ionization of acidic MetHb, there is a slight shift in the absorption spectrum of the conjugate acidic form at very low $I$ (George \& Hanania, 1953), and as a result of this the apparent ionization constant $\mathrm{p} K^{\prime}$ changes in a uniform manner over the whole pH range 8-10 at low $I$, the effect becoming progressively more pronounced at lower values of $I$. However, the ionization constant of MetMb calculated from measurements between $\mathrm{pH} 8.6$ and $9 \cdot 3$ is constant even at the lowest values of $I$, and so the factor which makes $\mathrm{p}^{\prime}$ a variable in the ionization of MetMb cannot be the same (spectroscopic) factor operative with MetMb. Likewise it can be shown that a similar shift in the absorption spectrum of alkaline MetMb would also effect $\mathbf{p}^{\prime}$ throughout the entire $\mathrm{pH}$ range, and not merely outside the range $8 \cdot 6-9 \cdot 3$.

It seems reasonable therefore to conclude that the above results arise from a genuine chemical effect. On this basis, following the argument used in paper 1, we may take a simple Debye-Hückel model for calculating the effective (ionic strength) charge, $Z$, on the haematin iron atom from the limiting slopes in Fig. 2. To the nearest whole number, we find that upon ionization at $\mathrm{pH} 7 \cdot 8 \mathrm{Z}$ changes from +1 to 0 , whereas between $\mathrm{pH} 8 \cdot 6$ and 9.3 it changes from -2 to -3 , and at $\mathrm{pH} 9 \cdot 8$ from -4 to -5 .

The corresponding change in the formal charge on the iron atom accompanying the ionization of acidic MetMb is +1 to 0 in every case. That is, the effective charge on the iron atom in acidic MetMb is like the formal charge, +1 , at $\mathrm{pH} 7.8$ even in solutions of extremely low $I$. However, in more alkaline solutions the value of $Z$ changes progressively to -2 at $\mathrm{pH} 9$ and to -4 to $\mathrm{pH} 9 \cdot 8$, and the general trend in the results suggests that this value could well rise above -4 in still more alkaline solutions.

Can the equivalent of five negative charges be produced between pH 8 and 10? The acid-base titration curve of MetMb shows that the net negative charge on the molecule is about 10 at pH 9 and about 20 at pH 10 (George \& Irvine, 1955), but it is not clear how the electrostatic effect of these groups is transmitted to the haematin iron. We have previously suggested that a distinction can be made between this effect and the well-known 'haem-linked effect' (George \& Hanania, 1954c). With MetMb there is a clearly marked haem-linked effect which can be accounted for adequately in terms of one acidic group with $\mathrm{p} K^{\prime} \approx 6.0$ at $20^{\circ}$, and which will therefore be almost entirely in its con- jugate basic form in solutions alkaline to $\mathrm{pH} 8$ (George \& Hanania, 1955). Moreover, this effect is operative at high as well as low $I$. On the other hand, the phenomenon described in this paper appears only at very low $I$, and is completely suppressed by salt concentrations whose ionic strength exceeds $0 \cdot 1$. Accordingly, whatever the chemical nature of these groups, they must be regarded as having no special stereochemical configuration or chemical bonding relative to the haematin iron atom. The possible role which cationic acids may play in producing this effect has been discussed in some detail (George \& Hanania, 1954c).

As to the magnitude of this effect, it can be seen from Fig. 2 that the maximum difference between $\mathrm{p} K^{\prime}$ values is at $I=0$, and is 0.44 unit at $20^{\circ}$ between $\mathrm{pH} 7.8$ and 9.8 . In terms of free energy this amounts to about $0.6 \mathrm{kcal} . / \mathrm{mole}$. Since the standard free energy of ionization of acidic MetMb is $12.1 \mathrm{kcal}$. $/$ mole at $20^{\circ}$, this effect is seen to alter the free energy by about $5 \%$ at its maximum, and it may therefore be described as a second-order effect. Nevertheless, this indicates the extent to which ionizations on the protein influence the acid-base equilibrium of the iron-bound water molecule.

There are severe complications in carrying out a similar investigation of the methaemoglobin ionization, notably the change in the absorption spectrum of the conjugate acid at low $I$, but a rough estimate of the corresponding effect may be made from a comparison between the 'critical' ionic strengths in MetMb and MetHb, i.e. the values of $I$ at which the $\mathrm{p} K^{\prime}-\sqrt{ } I$ curve changes the sign of its slope. Spectrophotometric studies of the ionization of acidic MetHb (George \& Hanania, 1953) showed that the critical $I$ for MetHb is about 0.1 compared to 0.01 for MetMb, and that the limiting slopes of their $\mathrm{p} K^{\prime}-\sqrt{ } I$ plots in the $\mathrm{pH}$ range 8.6-9.3 are about equal. If it is assumed that the behaviour of the two haemoproteins is similar, i.e. with the same limiting slopes at $\mathrm{pH} 7 \cdot 8$ and at $\mathrm{pH} 9 \cdot 8$, then the maximum difference in $\mathrm{pK}$ between $\mathrm{pH} 7.8$ and 9.8 in the ionization of MetHb would be about three times the difference found with MetMb, and the corresponding difference in free energy would be about $1.9 \mathrm{kcal} . /$ mole. At $20^{\circ}$, the standard free energy of ionization of acidic MetHb is $11.9 \mathrm{kcal} . / \mathrm{mole}$; hence the free energy would be altered by about $16 \%$ at its maximum, which is considerably greater than with MetMb. Thus we may conclude that in the MetHb ionization, with its larger critical $I$, there might be a bigger difference in $\mathrm{p} K_{0}$ values between $\mathrm{pH} 7 \cdot 8$ and $\mathbf{9 \cdot 8}$, which would be attributable to a stronger interaction between the haematin iron atom of $\mathrm{MetHb}$ and ionizing groups on the protein.

A similar conclusion follows from the assumption that the critical $I$ represents the point of departure from simple Debye-Hückel behaviour at the 
particular pH owing to the screening of the haematin iron atom from the influence of the various ionizing groups. On this basis a larger critical $I$ would signify that a larger concentration of salt ions is required for complete screening, and hence that there is a stronger interaction between the iron and the ionizing groups in MetHb.

In conclusion, although the mechanism may be different it may be noted that the Bohr effect, which is due to interaction between the iron and the specific haem-linked ionizing group, is greater in haemoglobin than in myoglobin.

\section{SUMMARY}

1. The ionization constant of the iron-bound water molecule in acidic metmyoglobin has been measured from about $\mathrm{pH} 7$ to 10 at eight ionic strengths of buffer solution ranging from 0.40 to 0.002 . The values confirm the conclusion suggested by the measurements reported in paper 1 (George \& Hanania, 1952) that the ionization constant is independent of $\mathrm{pH}$ only in the presence of appreciable concentrations of neutral salt.

2. At $I=0.40$ at $20^{\circ}, \mathrm{p} K^{\prime}$ is 8.98 throughout the $\mathrm{pH}$ range $7 \cdot 5-9 \cdot 8$, but at $I<0 \cdot 02, \mathrm{p} K^{\prime}$ decreases as $\mathrm{pH}$ is decreased below 8.6 , and it increases as $\mathrm{pH}$ is increased above $9 \cdot 3$.

3. The extrapolation of $\mathrm{p} K^{\prime}$ values plotted against $\sqrt{I} /(1+\sqrt{I})$ to zero ionic strength gives $\mathrm{p} K_{0}$ values of $8.81,9.07$ and 9.25 at $\mathrm{pH} 7.8$, between $\mathrm{pH} 8 \cdot 6$ and $9 \cdot 3$ and at $\mathrm{pH} 9 \cdot 8$ respectively.

4. It is suggested that this variation of the free energy of ionization with $\mathrm{pH}$ is due to an unspecific interaction between charged groups on the protein moiety and the haematin iron atom, which is observable only at low $I$ because of the screening effect of neutral salt ions. In contrast, the effect of a specific haem-linked ionizing group is observable at all ionic strengths.

5. The limiting slopes of the $\mathrm{p} K^{\prime}$ plots are approximately $+0.5,-2.5$ and -4.5 at $\mathrm{pH} 7.8$,

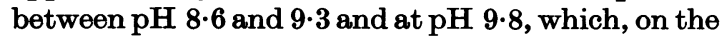
basis of a simple Debye-Hückel model may be attributed to the effective charge of the haematin iron atom changing upon ionization from +1 to 0 , from -2 to -3 and from -4 to -5 respectively.

The work reported above forms part of a research programme supported by grants from the Medical Research Council and the Nuffield Foundation which we gratefully acknowledge.

\section{REFERENCES}

Barnard, R. D. (1944). J. biol. Chem. 153, 91.

Bates, R. G., Pinching, G. D. \& Smith, E. R. (1950). J. Res. nat. Bur. Stand. 45, 418.

Duve, C. de (1948). Acta chem. scand. 2, 264.

George, P. \& Hanania, G. I. H. (1952). Biochem. J. 52, 517. George, P. \& Hanania, G. I. H. (1953). Biochem. J. 55, 236.

George, P. \& Hanania, G. I. H. (1954a). Biochem. J. 56, xxxvii.

George, P. \& Hanania, G. I. H. (1954b). Biochem. J. 56, xxxviii.

George, P. \& Hanania, G. I. H. (1954c). Nature, Lond., 174, 33.

George, P. \& Hanania, G. I. H. (1955). Disc. Faraday Soc. $20,216$.

George, P. \& Irvine, D. H. (1952). Biochem. J. 52, 511.

George, P. \& Irvine, D. H. (1955). Biochem. J. 60, 596.

Theorell, H. \& Åkeson, A. (1955). Ann. Acad. Sci. fenn. A II, 60, 303.

\title{
The Sulphydryl Groups of Sickle-cell Haemoglobin
}

\author{
By V. M. INGRAM \\ Medical Research Council Unit for the Study of the Molecular Structure of Biological Systems, \\ Cavendish Laboratory, University of Cambridge
}

(Received 27 September 1956)

In patients with homozygous sickle-cell anaemia the red blood corpuscles become distorted into sickle shapes at low oxygen pressure, apparently due to the formation of liquid crystals of reduced haemoglobin. Such liquid crystals can also be formed in vitro by reduction of purified solutions of sickle-cell haemoglobin, a phenomenon which is apparently due to the abnormally low solubility of sickle-cell haemoglobin in the reduced state (Perutz \& Mitchison, 1950; Perutz, Liquori \& Eirich, 1951). The formation of liquid crystals can be inhibited and the solubility restored to normal by reaction with SH group inhibitors such as silver and mercury ions and mercury derivatives (Thomas \& Stetson, 1948; Ingbar \& Kass, 1951). Presumably the sulphydryl groups are closely involved in the 'sickling' process. Ingbar \& Kass (1951) made a study of the number of available SH groups with amperometric silver nitrate titrations and made the significant observation that there were apparently two SH groups in normal but three in sickle-cell haemoglobin (haemoglobin A and S respectively). 